\title{
Robust expression of Prominin-2 all along the adult male reproductive system and urinary bladder
}

\author{
József Jászai · Christine A. Fargeas • Michael Haase • \\ Lilla M. Farkas · Wieland B. Huttner · Denis Corbeil
}

Accepted: 11 May 2008 / Published online: 7 June 2008

(C) The Author(s) 2008

\begin{abstract}
Although the male reproductive system seems to be enriched in transcripts encoding for both Prominin genes, little is known about their spatial distribution in distinct segments of this organ system. This is especially true for the less-characterized second Prominin paralogue, Prominin-2. The present study, therefore, mainly examines the expression of Prominin-2 in male mice and reveals the existence of some crucial differences in the tissue compartmentalization of the two Prominin paralogues in the testis, epididymis, seminal vesicle, prostate and urinary bladder. Our in situ hybridization analysis demonstrates that the major domains of overlapping expression between the two Prominin genes are those compartments that are derived ontogenetically from the epigonadal mesonephric tubules, i.e. ductuli efferentes, or from the Wolffian-tube/ductus mesonephricus, for instance the corpus epididymidis and vesicula seminalis. In contrast, the sinus urogenitalis derivative
\end{abstract}

J. Jászai $(\varangle)$ · C. A. Fargeas · D. Corbeil $(\square)$

Tissue Engineering Laboratories,

BIOTEC and DFG Research Center and Cluster of Excellence

for Regenerative Therapies Dresden (CRTD),

Technische Universität Dresden, Tatzberg 47-49,

01307 Dresden, Germany

e-mail: jozsef.jaszai@biotec.tu-dresden.de

D. Corbeil

e-mail: corbeil@biotec.tu-dresden.de

M. Haase

Department of Pathology and OncoRay,

Center for Radiation Research in Oncology,

Medical Faculty Carl Gustav Carus,

Technische Universität Dresden,

Fetscherstrasse 74, Dresden, Germany

L. M. Farkas · W. B. Huttner

Max-Planck-Institute of Molecular Cell Biology and Genetics,

Pfotenhauerstrasse 108, 01307 Dresden, Germany urinary bladder epithelium expresses exclusively Prominin2, but not Prominin-1 (CD133). The testis expresses only Prominin-1, not Prominin-2. In human prostate, we finally demonstrate that the expression of Prominin-2 (transcript and protein) is highly enriched in cells located in the basal compartment of the glandular epithelium where only a minute population was recently reported to be Prominin-1 positive. Taken together our data indicate that, except for the gonad, Prominin-2 is widely and abundantly expressed along the epithelia of various segments of the adult male genitourinary tract.

Keywords Prominin - Prostate - Testis - Epididymis . Seminal vesicle $\cdot$ Urinary bladder

\section{Introduction}

Prominins are evolutionarily conserved integral plasma membrane proteins (Corbeil et al. 2001a, b; Fargeas et al. 2003a) showing specific subcellular compartmentalization when studied in models of polarized epithelial and non-epithelial cells (Weigmann et al. 1997; Corbeil et al. 1999; Florek et al. 2007). The prototype of this unusual pentaspan glycoprotein family, Prominin-1 (CD133) (Weigmann et al. 1997; Miraglia et al. 1997), appears to be an apically restricted marker of embryonic- and adult epithelial cells having a propensity to be localized in various plasma membrane structures protruding from the planar surface, e.g. microvillus (Weigmann et al. 1997; Marzesco et al. 2005), flagellum (Fargeas et al. 2004) and primary cilium (Janich and Corbeil 2007; Dubreuil et al. 2007; Florek et al. 2007). The cellular expression of Prominin-1 has been documented in the murine and human embryonic neuroepithelium, mesonephros, metanephric proximal tubules, epididymis, 
intercalated ducts of salivary- and lacrimal glands, pancreas (Weigmann et al. 1997; Corbeil et al. 2000; Fargeas et al. 2004; Florek et al. 2005; Jászai et al. 2007a; Gashaw et al. 2007; Oshima et al. 2007; Lardon et al. 2008) and in the epithelial-derived photoreceptor cells (Maw et al. 2000; Jászai et al. 2007b). Prominin-1 is also expressed in nonepithelial cells, notably hematopoietic stem and progenitor cells (Yin et al. 1997; Corbeil et al. 2000; Freund et al. 2006). Prominin-1 is, by now, one of the most extensively studied cell surface markers of somatic stem and progenitor cells (Weigmann et al. 1997; Yin et al. 1997; Richardson et al. 2004; Lee et al. 2005; Bussolati et al. 2005; Yamada et al. 2007; for review see Fargeas et al. 2006) and cancer stem cells (Singh et al. 2003, 2004; Collins et al. 2005; Florek et al. 2005; Bao et al. 2006; Ricci-Vitiani et al. 2007; O'Brien et al. 2007).

Mammalian genomes contain a Prominin paralogue, named Prominin-2, showing the typical pentaspan membrane topology of Prominin-1. This second, yet less characterized Prominin shares only a moderate $(\approx 30 \%)$ amino acid identity with Prominin-1 (Corbeil et al. 2001b; Fargeas et al. 2003a). In contrast to the apically restricted Prominin1 , Prominin-2 is also expressed in basolateral plasma membrane of polarized epithelial cells (Florek et al. 2007; Jászai and Corbeil, unpublished data). The physiological function of these cholesterol-binding proteins is currently unknown (Röper et al. 2000; Florek et al. 2007).

Previous tissue expression profiling experiments (i.e. dot blot arrays) have shown that Prominin-2 transcripts exhibit a partial overlap with that of Prominin- 1 revealing a differential expression of the two paralogues in various organ systems among others in the male genitourinary tract (Fargeas et al. 2003a; Florek et al. 2005). There, an overlapping signal was observed only in the metanephros but not in other organs of the apparatus represented on the arrays (Fargeas et al. 2003a; Florek et al. 2005). On the other hand these arrays contained no material derived for instance from the epididymis or seminal vesicle making the picture very fragmentary. Nevertheless, immunohistochemical analysis has revealed that beside the testis, the epididymis also expresses Prominin-1 (Fargeas et al. 2004). Prominin-2 seems to be particularly enriched in the rat prostate, where it was described as a novel prominin-like protein encoded by an androgen-responsive gene in the ventral prostate (Zhang et al. 2002). Similarly, expression of PROMININ-2 in the human prostate and prostate cancer cell lines of human origin was also demonstrated on tissue-specific Northern blots (Zhang et al. 2002; Fargeas et al. 2003a). In contrast, Prominin-1 (i.e. its particular AC133 epitope) in the human prostate was detected only in a very rare subset of basal cells with stem cell features (Richardson et al. 2004).

Our knowledge is rather incomplete concerning spatial distribution/anatomical niches of both Prominin molecules within the male genitourinary tract. This especially holds true for Prominin-2 within this organ system. Therefore, the present study examines the expression of Prominin-2 in the adult murine male reproductive tract as well as urinary bladder, and in the adult human prostate. Our results indicate that except for the gonad Prominin-2 gene is expressed more abundantly than Prominin-1 in the epithelium of various segments of the genitourinary tract. In human prostate, ProminIN-2 appears restricted to the cells found in the basal part of the epithelium indicating that this plasma membrane protein might be a novel molecular marker of the morphological segregation of epithelial cells into basal and luminal compartments.

\section{Materials and methods}

Tissue samples

Adult murine organ samples were obtained from C57BL/6 strain. Male mice ( 6 months) were deeply anesthetized by a single intra-peritoneal bolus injection of Ketamine and Xylazin mixture. Animals were then trans-cardially perfused with ice-cold $4 \%$ paraformaldehyde (PFA). The organs were removed and post-fixed in $4 \% \mathrm{PFA}$ for $2 \mathrm{~h}$ at $4^{\circ} \mathrm{C}$. After cryoprotection with $30 \%$ sucrose-PBS tissue samples were embedded in OCT compound (Tissue Tek, Sakura, The Netherlands). Samples were sectioned on a cryostat (HM560, Microm International GmbH, Walldorf, Germany) at $12 \mu \mathrm{m}$ and then mounted onto SuperFrost ${ }^{\circledR}$ Plus microscope slides (Menzel-Gläser, Braunschweig, Germany), dried overnight at room temperature, and stored at $-20^{\circ} \mathrm{C}$ until use.

Normal tissue from adult human prostate was obtained from anonymous archival material that had not been used for further histopathological or genetic analysis at the Department of Pathology, University of Technology Dresden. The dissected tissue was snap frozen in liquid nitrogen, and stored in a liquid nitrogen tank in the archive until use. The frozen tissue was then cryosectioned at $10 \mu \mathrm{m}$ and sections were mounted onto SuperFrost ${ }^{\circledR}$ Plus microscope slides (Menzel-Gläser). Sections were dried for $3 \mathrm{~h}$ at room temperature then the slides were transferred to $-80^{\circ} \mathrm{C}$. Alternatively, the sample was used to prepare membrane lysates according to procedures reported previously (Corbeil et al. 2001a). Protein concentrations were determined using BCA Protein Assay Reagent (Pierce Biotechnology, Inc., Rockford, IL, USA).

Non-radioactive in situ hybridization

In situ hybridization (ISH) on fresh frozen human or 4\% PFAfixed mouse cryosections was performed according to standard protocols (Tiveron et al. 1996). Briefly, serial sections were hybridized with digoxygenin (DIG) labeled cRNA 
probes (see below) at a concentration of $0.5 \mathrm{ng} / \mu \mathrm{l}$ for $16 \mathrm{~h}$ at $70^{\circ} \mathrm{C}$. Stringency washes were performed at $70^{\circ} \mathrm{C}$. The sections were then incubated with anti-DIG antibody (1:4000; Roche Molecular Biochemicals, Mannheim, Germany) for $16 \mathrm{~h}$ at $4^{\circ} \mathrm{C}$. After several washing steps the reaction was visualized using NBT-BCIP substrate (Roche Molecular Biochemicals) giving a blue reaction product. After stopping the color reaction by several washes in PBS, the sections were rinsed quickly in $\mathrm{dH}_{2} \mathrm{O}$ and then mounted with Kaiser's Glycerol-Gelatin (Merck, Darmstadt, Germany). Images were captured using an Olympus BX61 microscope with the IPLAB software. The composite images were prepared from the digital data files using Adobe Photoshop and Illustrator.

\section{Probes for in situ hybridization}

Antisense complementary DIG-labeled ribonucleic acid (cRNA) probes were generated using T7 RNA polymerase and DIG labeling mix (Roche Molecular Biochemicals). To synthesize murine Prominin-1 (Accession Number AF026269) and Prominin-2 (Accession Number AF269062) cRNA probes a $2.1 \mathrm{~kb}$ (nt 198-2,264) and a $1.9 \mathrm{~kb}$ (nt 346-2,258) cDNA fragment was used, respectively. To synthesize human PROMININ-2 (Accession Number AF245303) cRNA probe a $1.7 \mathrm{~kb}$ (nt 128-1,834) cDNA fragment was used. The average homology of the murine Prominin paralogues along the stretch used for ISH is about $45 \%$. This precludes any crosshybridization combined with the stringent hybridization and post-hybridization washing conditions used.

\section{Immunohistochemistry}

Immunohistochemical (IHC) detection of human PROMININ-2 was performed on serial cryostat sections prepared from fresh frozen prostate specimen as follows. Cryosections were brought to room temperature and fixed with $4 \%$ PFA for $30 \mathrm{~min}$. Sections were washed twice with PBS, then the endogenous peroxidase activity was blocked with $2 \% \mathrm{H}_{2} \mathrm{O}_{2}$ for $30 \mathrm{~min}$ followed by washes for three times $5 \mathrm{~min}$ in PBS. The sections were subsequently incubated with $0.005 \% \mathrm{SDS}$ in $0.2 \%$ gelatin-PBS for $30 \mathrm{~min}$. The samples were then rinsed with $0.2 \%$ gelatin-PBS followed by three changes of $0.15 \%$ saponin in $0.2 \%$ gelatin-PBS for 30 min each. Sections were incubated overnight at $4{ }^{\circ} \mathrm{C}$ with anti-human PROMININ-2 mouse monoclonal antibody (mAb) 2024 (1:1,000; clone 244029; R\&D Systems, Minneapolis, MN, USA) diluted in $0.15 \%$ saponin in $0.2 \%$ gelatin-PBS. The samples were then extensively washed with $0.15 \%$ saponin in PBS followed by a washing step with $0.15 \%$ saponin in $0.2 \%$ gelatin-PBS for $30 \mathrm{~min}$. The primary antibody was detected with a biotinylated horse antimouse secondary antibody (1:500; Vector Laboratories, Burlingame, CA, USA), avidin-biotin-peroxidase complex
(ABC Elite Vectastain kit, Vector Laboratories) and DAB chromogen. In order to facilitate the identification of the glandular epithelial cells according to their typical nuclear configurations the immunolabeled slides were counterstained with 4,6-diamidino-2-phenylindole (DAPI). After washing once with PBS, slides were mounted with Kaiser's Glycerol-Gelatin (Merck). Images were captured using an Olympus BX61 microscope with the IPLAB software.

\section{SDS-PAGE and immunoblotting}

Membrane lysates from adult human prostate $(50 \mu \mathrm{g}$ protein) were analysed by SDS-polyacrylamide-gel electrophoresis (SDS-PAGE; 7.5\%) and transferred to poly(vinylidene difluoride) (PVDF) membranes (Millipore Corp., Bedford, MA; pore size $0.45 \mu \mathrm{m}$ ) using a semi-dry transfer cell system (Cti, Idstein, Germany) as described (Corbeil et al. 2001a). After transfer, membranes were incubated overnight at $4{ }^{\circ} \mathrm{C}$ in blocking buffer (PBS containing 5\% low fat milk powder and $0.3 \%$ Tween-20). Human PROMININ-2 was then detected using mouse mAb 2024 $(1: 1,000)$ diluted in blocking buffer. Incubations were performed for $1 \mathrm{~h}$ at room temperature. Antigen-antibody complexes were revealed using horseradish peroxidaseconjugated secondary antibodies (Dianova) followed by enhanced chemiluminescence (ECL system, Amersham).

Anatomical terminology

To designate a particular anatomical structure, we have simultaneously used the English terminology gaining increasing popularity and the traditional Latin anatomical terminology based on Nomina Anatomica Veterinaria $(N A V)$ and Terminologia Anatomica $(T A)$.

\section{Results}

The tissue distribution of both murine Prominin molecules in organs of the adult male reproductive tract and in the urinary bladder was investigated by ISH. In addition, the expression of human PROMININ-2 in the prostate was analysed by means of ISH and IHC since the tissue localization of this molecule is not yet documented in this clinically important organ.

Expression of Prominin-1, but not Prominin-2, in the murine testis

Expression of Prominin-1 gene was found to be restricted to the luminal zone of the contorted seminiferous tubules (tubuli seminiferi contorti) harboring spermatids (Fig. 1A, A', B; black hollow arrows) and absent from the basal part of these 
tubules containing the actively dividing spermatogonia (Fig. 1A, $\mathrm{A}^{\prime}, \mathrm{B}$; black asterisks). This is in keeping with the fact that spermatids undergo a differentiation procedure during spermio(histo)genesis. These originally round cells become highly polarized extending a large tubulin-based cilium, the so-called flagellum, where Prominin-1 protein localizes (Fargeas et al. 2004). The late elongated spermatids and spermatozoa were negative for the Prominin-1 transcript (Fig. 1A, A', B; white asterisks; see also Fig. 2A, C). In contrast, the expression of Prominin-2 was not detected in any of these compartments (Fig. 1C; white hollow arrow). The testicular interstitium containing steroid secreting Leydig cells and testicular macrophages was expressing neither Prominin-1 nor Prominin-2 (Fig. 1A', C; black arrowhead).

\section{Expression of Prominin-1 and Prominin-2 in the murine epididymis}

The epididymis is essentially composed of two major types of tubules: the so-called ductuli efferentes and the duct of the epididymis (ductus epididymidis). The first type of tubule in mice - in contrast to humans - is located outside of the head (caput) of the epididymis (Ilio and Hess 1994), while the latter one forms the head (caput), the body (corpus) and the tail (cauda) of the organ. Prominin-1 was detected in both the ductuli efferentes (Fig. 2A, DE; black hollow arrows) and the duct of the epididymis found in the corpus (Fig. 2C; black hollow arrow), but almost absent from the initial segment of the duct located in the proximal caput (Fig. 2A, IS; white arrow). Only a sporadic and weak staining was observed therein. Likewise, the expression of Prominin-1 was non-homogenous in the corpus with some cells expressing it while others appeared negative (Fig. 2C; white arrow). This is in keeping with previous findings on the expression of Prominin-1 protein using specific mAbs (Fargeas et al. 2004). In sharp contrast, Prominin-2 was found to be rather strongly and uniformly expressed in both types of tubules (Fig. 2B, DE, and D; black hollow arrows) including the initial segment of the duct of the epididymis (Fig. 2B, IS; black arrow).
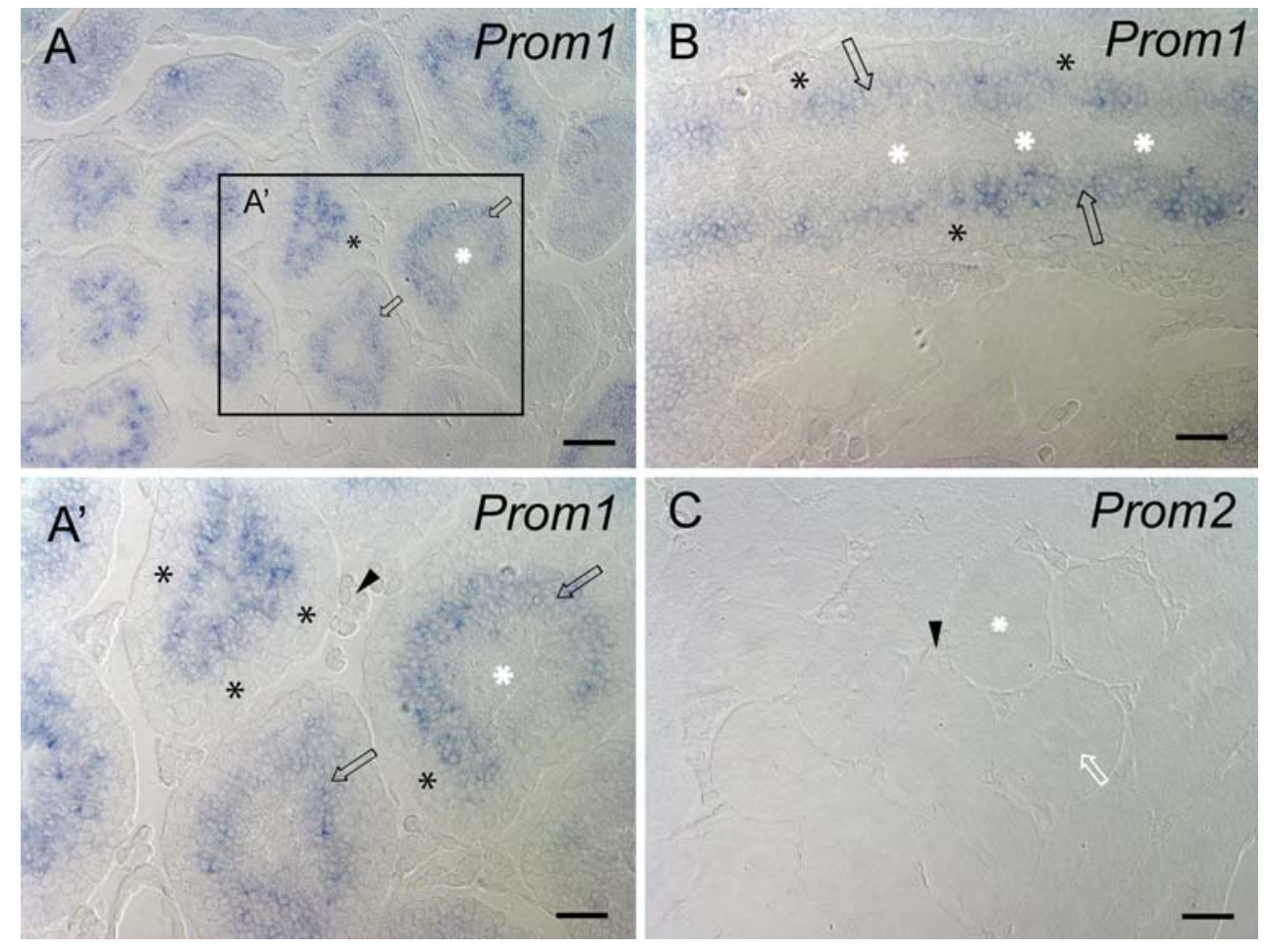

Fig. 1 Localization of Prominin-1 and Prominin-2 in the murine testis. Cryosections of testis were processed for non-radioactive ISH using either antisense DIG-labeled Prominin-1 (A, $\mathbf{A}^{\prime}, \mathbf{B}$, Proml) or Prominin-2 (C, Prom2) probes. The inset in panel A demarcates a region displayed at higher magnification in $\mathbf{A}^{\prime}$. (A, $\left.\mathbf{A}^{\prime}, \mathbf{B}\right)$ Black hollow arrows show Prominin-1-labeled cells (blue) located in the luminal zone of the contorted seminiferous tubules corresponding to spermatids while black asterisks indicate that the peripheral/basal part of these tubules is negative. Black arrowhead points to the interstitium containing Leydig cells and testicular macrophages that are negative. (C) White hollow arrow and black arrowhead indicate that both the seminiferous tubules and the interstitial cells of the testis are negative for Prominin-2, respectively. White asterisks label the lumen of the contorted seminiferous tubules. Bars $100 \mu \mathrm{m}$ in $\mathbf{A}, \mathbf{C} ; 50 \mu \mathrm{m}$ in $\mathbf{A}^{\prime}, \mathbf{B}$ 


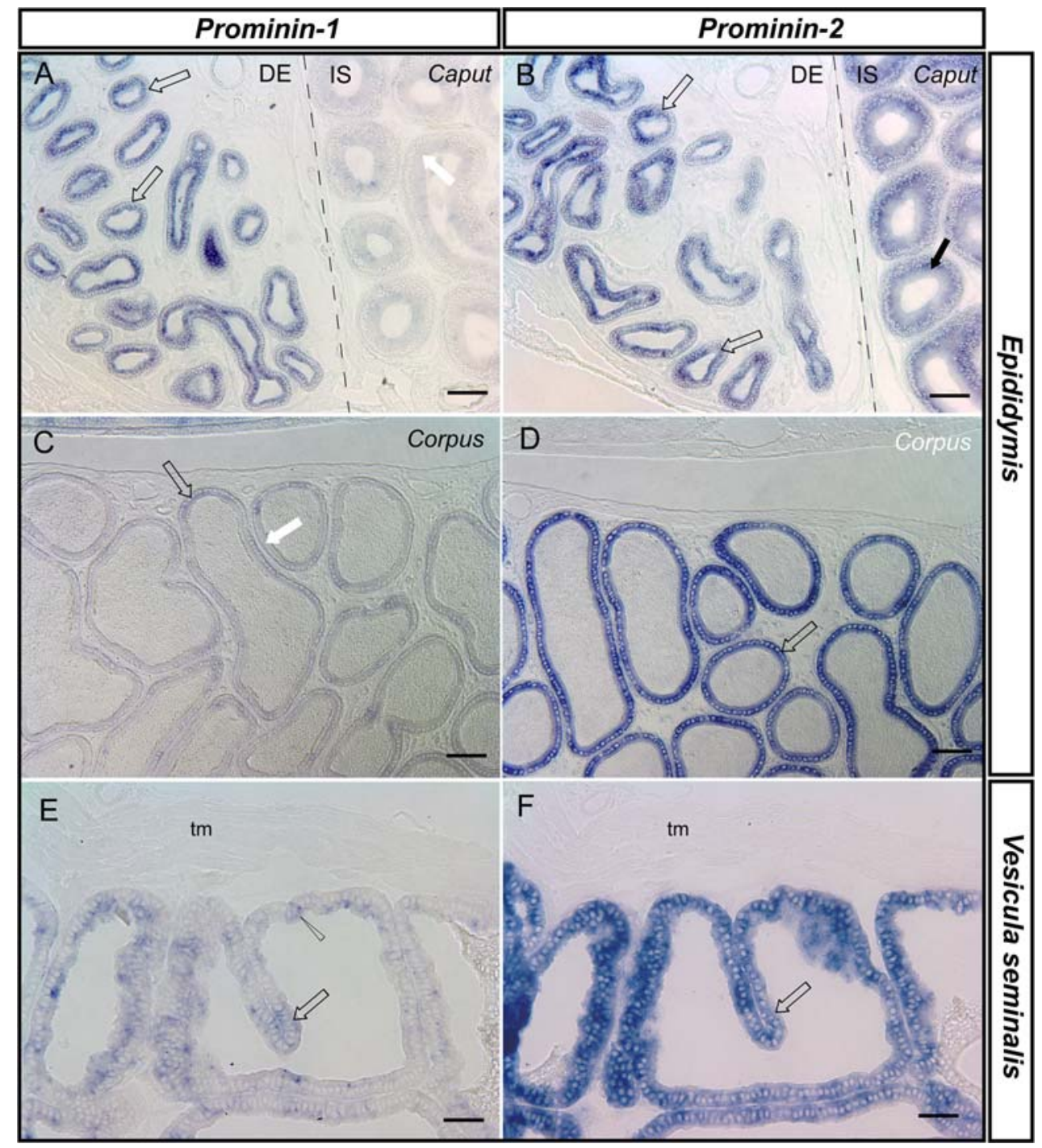

Fig. 2 Localization of Prominin-1 and Prominin-2 in the murine epididymis and seminal vesicle. Cryosections of epididymis (A-D) and seminal vesicle $(\mathbf{E}, \mathbf{F})$ were processed for non-radioactive ISH using either antisense DIG-labeled Prominin-1 (A, C, E) or Prominin-2 $(\mathbf{B}, \mathbf{D}, \mathbf{F})$ probes. $(\mathbf{A}, \mathbf{C})$ Black hollow arrows indicate the expression of Prominin-1 in efferent ducts $(\mathbf{A}, D E)$ and the duct located in the corpus epididymidis $(\mathbf{C})$. White arrows show the absence of Prominin-1 in the initial segment $(\mathbf{A}, I S)$ and some portion of the duct in the corpus epididymidis (C). E Black hollow arrowhead points to Prominin-1-labeled glandular epithelial cells located above the smooth muscle layer

Expression of Prominin-1 and Prominin-2 in the murine seminal vesicle (Vesicula seminalis)

There was no indication so far for the expression of Prominin-1 or Prominin-2 in the seminal vesicle, which produces a significant portion of the seminal fluid. The epithelium lining this large accessory genital gland forms frequently branching folds. Expression of Prominin-1 was detected in the epithelial cells lying either over the smooth muscle layer (tunica muscularis) (tm, tunica muscularis) and black hollow arrow indicates Prominin-1labeled cells on a fold of the epithelium of the seminal vesicle. B Black hollow and solid arrows indicate the expression of Prominin-2 in efferent ducts $(D E)$ and the initial segment $(I S)$ of the epididymis, respectively. D Black hollow arrow indicates the presence of Prominin-2-labeled cells in the corpus epididymidis. F Black hollow arrow indicates the presence of Prominin-2-labeled cells in the glandular epithelium of the seminal vesicle. DE Ductuli efferentes. Bars $100 \mu \mathrm{m}$ in $\mathbf{A}-\mathbf{D} ; 50 \mu \mathrm{m}$ in $\mathbf{E}, \mathbf{F}$

(Fig. 2E; black hollow arrowhead) or on emerging folds (Fig. 2E; black hollow arrow). The signal appeared to be weak and quite non-homogeneous, in a way similar to the labeling pattern seen in the duct of the epididymis (for comparison see Fig. 2C, corpus). Expression of Prominin-2, however, was more abundant and distributed in a relatively homogenous manner in the epithelial layer (Fig. 2F; black hollow arrow). The smooth muscle layer was devoid of both Prominin-1 and Prominin-2 (Fig. 2E, F, tm). 
Expression of Prominin-2 in the murine and human prostate (Prostata)

The expression of Prominin-2 in the prostate was first described in rats as an androgen responsive gene (Zhang et al. 2002). Analyzing its expression in the murine ventral prostate we have observed that the signal, was confined to the glandular epithelial cells (Fig. 3A; black arrows) just like in case of its rat orthologue. No staining was observed in prostatic stromal cells (Fig. 3A; black hollow arrowheads).

Prostatic expression of human PROMININ-2 was analyzed at both mRNA and protein levels. The epithelial lin- ing of the tubulo-alveolar main glands of the human prostate appears heterogeneous morphologically. Nevertheless, two major cell populations can be distinguished within the epithelium: the basal cells and the luminal secretory population. The former cells are considered to be the precursors of the latter ones (Aumüller 1991; Signoretti and Loda 2006). It is of note that a third, minor population of cells, the so-called neuroendocrine cells of neurogenic origin with unresolved physiological function, has also been described in the prostatic glandular epithelium (Noordzij et al. 1995; Aumüller et al. 1999).

Expression of the human PROMININ-2 transcripts was confined to the basal cell population of the epithelium

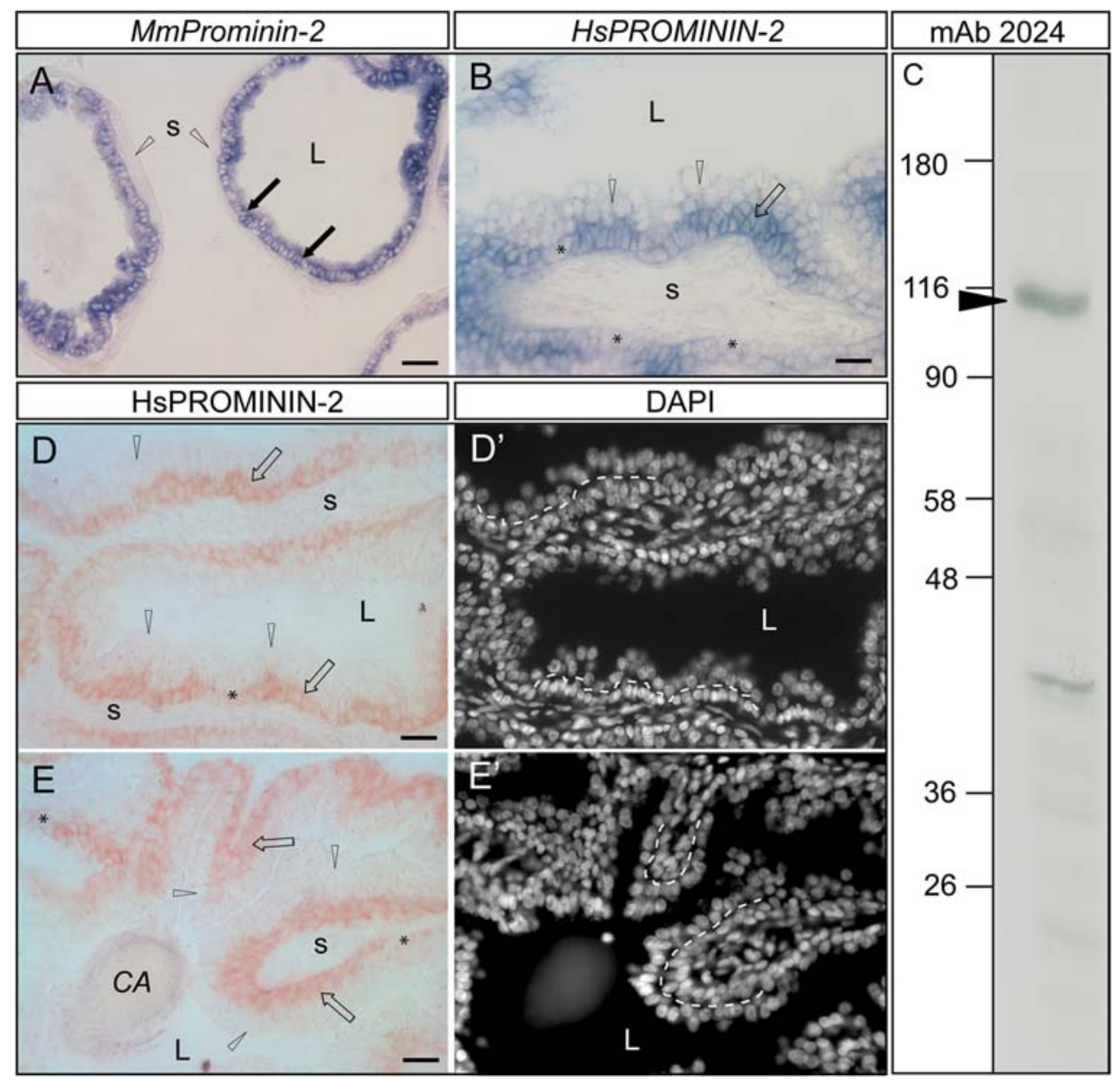

Fig. 3 Localization of Prominin-2 transcript in the murine ventral prostate and PROMININ-2 transcript and protein in the human prostate. Cryosections of murine ventral prostate (A) and human prostate $(\mathbf{B}, \mathbf{D}, \mathbf{E})$ were processed for non-radioactive ISH with antisense DIGlabeled Prominin-2 probes (A, B) or for IHC with the anti-PROMININ-2 mAb 2024 (D, E). A Black arrows indicate the expression of Prominin-2 in glandular epithelial cells (blue) of the murine ventral prostate. Stromal cells $(S)$ are negative (black hollow arrowheads). B Black hollow arrow indicates the presence of PROMININ-2 in the basal compartment of the epithelium of the human prostate. Black hollow arrowheads point to non-labeled luminal cells. Black asterisks indicate cells in the basal compartment with reduced signal intensity.
Stromal cells $(S)$ are negative. C Prominin-2 in adult human prostate is a 112 -kDa membrane protein. Proteins $(\approx 50 \mu \mathrm{g}$ ) solubilized from prostate membranes were analyzed by immunoblotting with the mAb 2024. Arrowhead indicates a 112-kDa immunoreactive band. D, E Black hollow arrows indicate PROMININ-2 positive cells (brown) located in the basal compartment, and black hollow arrowheads indicate negative cells in the luminal compartment. Black asterisks indicate basal cells displaying a weaker PROMININ-2 immunoreactivity. Nuclear architecture within the glandular epithelium is visualized using a DAPI staining ( $\mathbf{D}^{\prime}, \mathbf{E}^{\prime}$; white nuclei). White dashed lines indicate the border between the basal and luminal compartments $\left(\mathbf{D}^{\prime}, \mathbf{E}^{\prime}\right)$. L Lumen; $C A$ Corpus amylaceum. Bars $50 \mu \mathrm{m}$ in $\mathbf{A} ; 25 \mu \mathrm{m}$ in $\mathbf{B}, \mathbf{D}, \mathbf{E}$ 
(Fig. 3B; black hollow arrow) while no expression could be seen in luminal cells of the emerging epithelial folds (Fig. 3B; black hollow arrowheads). This observation was even more striking upon detecting PROMININ-2 protein. IHC was performed using the commercial anti-human PROMININ-2 mAb 2024. We have previously demonstrated the specificity of this antibody by immunoblotting of detergent lysates prepared from $\mathrm{CHO}$ cells transiently transfected with human PROMININ-2 plasmid, and shown that the corresponding epitope is partly dependent on the presence of $\mathrm{N}$-glycans (Jászai et al. 2007a). Similar analysis of adult human prostate membranes revealed a $112 \mathrm{kDa}-$ immunoreactive band, which is the expected molecular mass of PROMININ-2 (Fargeas et al. 2003a), indicating its expression in prostate (Fig. 3C; arrowhead). As for the ISH, the secretory cells facing the lumen were devoid of any immunoreactivity (Fig. 3D, E; black hollow arrowheads), while those located in deeper (basal) positions were labeled (Fig. 3D, E; black hollow arrows). The staining intensity with both ISH and IHC appeared to be somewhat heterogeneous, often being particularly strong in basal cells of the inward folds of the epithelium, while weaker in interfold regions (Fig. 3B, D, E; black asterisks).

\section{Expression of Prominin-2, but not Prominin-1,} in the murine urinary bladder (Vesica urinaria)

The epithelial lining of the urinary bladder is the so-called urothelium (transitional epithelium) in which three major cell types can be observed based on their relative position to the basement membrane. Our analysis revealed that Prominin-1 was not present (Fig. 4A, A') while Prominin-2 was abundantly expressed in the urothelium (Fig. 4B, B'). The signal was observable in all the major cell types (Fig. 4B'; black arrow/umbrella-Umbrella cell; black curved arrow/I-Intermediate cells; black arrowhead/BBasal cells). The lamina propria beneath the urothelium and the muscular tunica seemed to devoid of any detectable signal for both Prominin paralogues (Fig. 4A, B; lp, tm).

\section{Discussion}

In the present study, we have investigated the tissue compartmentalization of Prominin-2 in the adult male reproductive tract and urinary bladder in mice as well as in the human prostate. In essence, we report two major findings. First, Prominin-2 appears to be expressed more abundantly than Prominin- 1 in all organs of the adult male genitourinary tract analyzed with the notable exception of the gonad. Second, Prominin-2 is confined to the basal cells of the human prostatic glandular epithelium.

We demonstrated a robust expression of Prominin-2 all along the reproductive tract displaying, interestingly, only a partial overlap with Prominin-1. The differential expression appears both at organ and system level. For instance, Prominin-2 was detected uniformly in the duct of the epididymis while Prominin- 1 was almost absent from the initial segment
Fig. 4 Localization of Prominin-1 and Prominin-2 in the murine urinary bladder.

Cryosections of the urinary bladder were processed for nonradioactive ISH using either antisense DIG-labeled Prominin-1 (A) or Prominin-2 (B) probes. The insets in $\mathbf{A}$ and $\mathbf{B}$ demarcate regions displayed at higher magnification in $\mathbf{A}^{\prime}$ and $\mathbf{B}^{\prime}$, respectively. Prominin-1 (A, $\mathbf{A}^{\prime}$ ) does not produce any signal whereas Prominin-2 $\left(\mathbf{B}, \mathbf{B}^{\prime}\right)$ is abundantly expressed in the epithelium (urothelium) (blue) where the basal (B, black arrowhead), intermediate (I, black curved arrow) and Umbrella cells (umbrella symbol, black arrow) are all labeled. Other parts of the organ are negative. $\mathrm{L}$ Lumen; lp lamina propria; tm tunica muscularis. Bars $100 \mu \mathrm{m}$ in $\mathbf{A}, \mathbf{B} ; 50 \mu \mathrm{m}$ in $\mathbf{A}^{\prime}, \mathbf{B}^{\prime}$

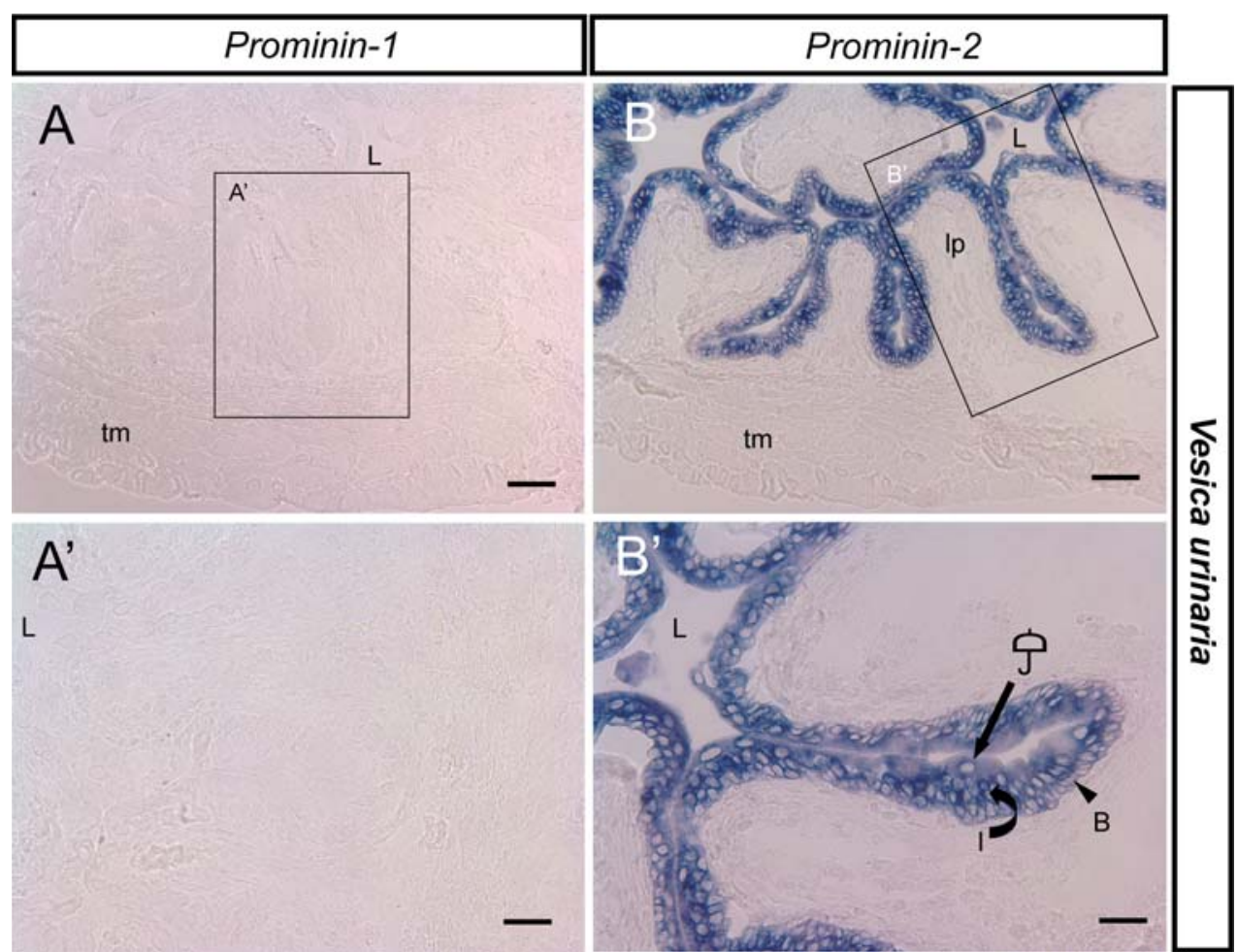


and distributed in a non-homogenous fashion in more downstream parts of this duct. A similar "salt-and-pepper"like pattern was revealed for Prominin-1 in the seminal vesicle as opposed to the rather uniform distribution of Prominin-2. Such information indicates that the regulation of the Prominin-2 gene may be less stringent than its paralogue not only between distinct segments/tissues, but also within a particular epithelium.

Prominin-2 appeared to be absent from the mouse germline derived cells in contrast to Prominin-1 which expression coincides with spermio(histo)genesis whereby the maturing spermatids become highly polarized and extend a large tubulin-based flagellum. We have previously demonstrated that Prominin-1 is selectively concentrated in this particular plasma membrane protrusion (Fargeas et al. 2004). Interestingly, a recent study on human tissue, while confirming the presence of Prominin-1 in the epididymal epithelium reported in contrast sporadic immunostaining in testicular tissue confined to spermatogonia and no immunoreactivity in flagella of spermatozoa anchored by Sertoli cells (Gashaw et al. 2007). Whether this discrepancy conveys constitutive differences between both species or results from the expression of alternative isoforms of Prominin-1 that would interfere with its detection like demonstrated in the murine system (Fargeas et al. 2004) would need further investigation. It is of note in this context that human Prominin- 1 may also undergo alternative splicing (Yu et al. 2002; Shmelkov et al. 2004; Fargeas et al. 2003b, 2007).

Our observation that Prominin-2 is predominantly expressed in the basal cells of the human prostatic epithelium is in line with the differential gene expression observed between cells morphologically segregated into basal and luminal compartments (Terpe et al. 1994; Signoretti et al. 2000; Tokar et al. 2005). Although not free from controversies, several observations indicate that basal and secretory cells are hierarchically related, where basal cells represent (or include) the progenitors for terminally differentiated luminal ones implying that the adult stem cells responsible for homeostatic replacement reside in the basal compartment (Aumüller 1991; Bonkhoff and Remberger, 1996; Robinson et al. 1998; Signoretti et al. 2005; Signoretti and Loda 2006). In accordance with that, it was reported that the basal compartment of the adult human prostatic epithelium harbors a rare, minute population of cells (about 1\%) expressing Prominin-1 (AC133 epitope) with stem cell properties (Richardson et al. 2004; Tsujimura et al. 2007). Whether these cells express simultaneously Prominin-2 requires further characterization.

The cells located basally are markedly distinct from the luminal ones in their proliferative capacity. Indeed, the proliferative compartment of the normal and hyperplastic prostatic epithelium seems to be located in the basal part
(Bonkhoff et al. 1994). Importantly, the increase in cell proliferation observed in basal cell hyperplasia [benign prostatic hyperplasia] might be an important intermediate step [precancerous lesion] toward prostate cancer initiation, and early progression as cancer stem/tumor initiating progenitor cells are likely transformed from hyperplastic basal cells (Wang et al. 2006; Chen et al. 2007). It is particularly relevant that very rare AC133-positive tumorigenic cancer stem cells were identified in prostate tumors (Collins et al. 2005; Rizzo et al. 2005; Miki et al. 2007). Differential gene expression studies revealed that a number of basal cell markers were expressed as well by cancer cells especially by those that were poorly differentiated (McDonnell et al. 1992; Liu et al. 1996). Expression of Prominin-2, however, was hardly detectable by northern blot in prostate cancer cells (Zhang et al. 2002). Consistently, among the prostatic carcinoma cells of human origin commonly studied, e.g. DU145, PC3 and LNCaP, only the latter showed good expression of Prominin-2 as assessed by PCR (Zhang et al. 2002). Inasmuch as these prostate cancer cells predominantly display more luminal, secretory-like phenotypes this might indicate that the differentiation grade of the prostate tumors could negatively correlate with Prominin-2 expression. Whether Prominin-2 might be a marker of both normal and/or tumor initiating progenitor cells or is expressed by the putative intermediate "transit amplifier" pool of cells with mixed immunophenotypic profile (van Leenders et al. 2000; Tran et al. 2002; Schalken and van Leenders 2003; Tokar et al. 2005) remains to be established. Likewise, the potential expression of PROMININ-2 by neuroendocrine cells being sparsely scattered between the basal and luminal layers (Noordzij et al. 1995) needs to be investigated as well. Nevertheless, being a transmembrane protein, PromININ-2 might be a valuable tool for prospective isolation and characterization of cells located in the basal part of the adult human prostatic epithelium.

It is of note that the expression of Prominin-2 in the human prostate is restricted to basal cells, which are androgen receptor (AR) negative or expressing it at very low level, given that the rat orthologue was first reported as a testosterone-regulated gene (Zhang et al. 2002). In fact, testosterone deprivation in the rodent castration model decreased Prominin-2 expression, and hormone replacement restored it. The basal cells lacking AR are known to be less sensitive to hormone withdrawal than the secretory (luminal) cells that undergo apoptosis following castration (English et al. 1989). The remaining basal cells are able to reconstitute the glandular epithelium upon testosterone administration. Since androgens have been described to exert both direct and indirect effects on prostatic epithelial cells (Sugimura et al. 1996), the testosterone induction of Prominin-2 observed by Zhang et al. (2002) could represent an indirect effect or alternatively correspond to a subpopulation 
of transit amplifying cells with mixed immunophenotype, which might be responsive to androgen replacement in the castration model. It cannot be excluded though that this might reflect differential regulation between rodents and humans, since an exclusively basal localization of Prominin-2 is neither in the mouse (present study) nor in the rat (Zhang et al. 2002) evident.

In the urothelium of the urinary bladder, a similar tendency of cellular segregation and differential expression of molecular markers are detectable as in the prostatic epithelium (Signoretti et al. 2005); yet, a distinctly different distribution is observed for Prominin-2. It seems to be rather uniformly expressed in all three major categories of cells located at different relative positions within the epithelium. Whether the expression of Prominin-2 reflects the common ancestry of the distinct cell types in a hierarchic cascade remains to be explored (Signoretti et al. 2005).

Until now no precise function has been demonstrated for Prominins. However, several lines of evidence suggest that these cholesterol-binding membrane proteins might play a role in plasma membrane protrusion morphogenesis and maintenance (for reviews see Corbeil et al. 2001b; Jászai et al. 2007b). Their expression in various epithelia of the male genitourinary tract containing distinct types of plasmalemma outgrowths, e.g. microvilli and motile cilia in the ductuli efferentes and stereocilia in the duct of the epididymis, is consistent with such a role.

Taken together our data indicate that the two Prominin paralogues although sharing many structural similarities (Fargeas et al. 2003a) have a different distribution along the male genitourinary tract. The widespread expression of Prominin-2 in epithelia derived either from mesoderm (epididymis, seminal vesicle) or endoderm (prostate, urinary bladder) suggests that this molecule might find an application as a general epithelial cell marker in the male urogenital apparatus.

\begin{abstract}
Acknowledgments We thank Suzanne Manthey, Sylvi Graupner and Ina Lehmann for the skillful assistance for preparing the cryosection samples. W.B.H. was supported by the Deutsche Forschungsgemeinschaft (SPP 1109, Hu275/7-3; SPP 1111, Hu275/8-3; SFB/ TR13-04 B1; SFB 655 A2), D.C. by the Deutsche Forschungsgemeinschaft (SPP 1109, CO 298/2-2; SFB/TR13-04 B1; SFB 655 A13) and the Saxonia Ministry of Science and Art-European Fond for Regional Development (4212/05-16).
\end{abstract}

Open Access This article is distributed under the terms of the Creative Commons Attribution Noncommercial License which permits any noncommercial use, distribution, and reproduction in any medium, provided the original author(s) and source are credited.

\section{References}

Aumüller G (1991) Postnatal development of the prostate. Bull Assoc Anat (Nancy) 75:39-42
Aumüller G, Leonhardt M, Janssen M, Konrad L, Bjartell A, Abrahamsson PA (1999) Neurogenic origin of human prostate endocrine cells. Urology 53:1041-1048

Bao S, Wu Q, McLendon RE, Hao Y, Shi Q, Hjelmeland AB, Dewhirst MW, Bigner DD, Rich JN (2006) Glioma stem cells promote radioresistance by preferential activation of the DNA damage response. Nature 444:756-760

Bonkhoff H, Stein U, Remberger K (1994) The proliferative function of basal cells in the normal and hyperplastic human prostate. Prostate $24: 114-118$

Bonkhoff H, Remberger K (1996) Differentiation pathways and histogenetic aspects of normal and abnormal prostatic growth: a stem cell model. Prostate 28:98-106

Bussolati B, Bruno S, Grange C, Buttiglieri S, Deregibus MC, Cantino D, Camussi G (2005) Isolation of renal progenitor cells from adult human kidney. Am J Pathol 166:545-555

Chen BY, Liu JY, Chang HH, Chang CP, Lo WY, Kuo WH, Yang CR, Lin DP (2007) Hedgehog is involved in prostate basal cell hyperplasia formation and its progressing towards tumorigenesis. Biochem Biophys Res Commun 357:1084-1089

Collins AT, Berry PA, Hyde C, Stower MJ, Maitland NJ (2005) Prospective identification of tumorigenic prostate cancer stem cells. Cancer Res 65:10946-10951

Corbeil D, Röper K, Hannah MJ, Hellwig A, Huttner WB (1999) Selective localization of the polytopic membrane protein prominin in microvilli of epithelial cells-a combination of apical sorting and retention in plasma membrane protrusions. J Cell Sci 112:1023-1033

Corbeil D, Röper K, Hellwig A, Tavian M, Miraglia S, Watt SM, Simmons PJ, Peault B, Buck DW, Huttner WB (2000) The human AC133 hematopoietic stem cell antigen is also expressed in epithelial cells and targeted to plasma membrane protrusions. J Biol Chem 275:5512-5520

Corbeil D, Fargeas CA, Huttner WB (2001a) Rat prominin, like its mouse and human orthologues, is a pentaspan membrane glycoprotein. Biochem Biophys Res Commun 4:939-944

Corbeil D, Röper K, Fargeas CA, Joester A, Huttner WB (2001b) Prominin: a story of cholesterol, plasma membrane protrusions and human pathology. Traffic 2:82-91

Dubreuil V, Marzesco AM, Corbeil D, Huttner WB, Wilsch-Bräuninger M (2007) Midbody and primary cilium of neural progenitors release extracellular membrane particles enriched in the stem cell marker Prominin-1. J Cell Biol 176:483-495

English HF, Kyprianou N, Isaacs JT (1989) Relationship between DNA fragmentation and apoptosis in the programmed cell death in the rat prostate following castration. Prostate 15:233-250

Fargeas CA, Florek M, Huttner WB, Corbeil D (2003a) Characterization of Prominin-2, a new member of the prominin family of pentaspan membrane glycoproteins. J Biol Chem 278:8586-8596

Fargeas CA, Corbeil D, Huttner WB (2003b) AC133 antigen, CD133, Prominin-1, Prominin-2, etc.: prominin family gene products in need of a rational nomenclature. Stem Cells 21:506-508

Fargeas CA, Joester A, Missol-Kolka E, Hellwig A, Huttner WB, Corbeil D (2004) Identification of novel Prominin-1/CD133 splice variants with alternative C-termini and their expression in epididymis and testis. J Cell Sci 117:4301-4311

Fargeas CA, Fonseca A-V, Huttner WB, Corbeil D (2006) Prominin-1 (CD133)-from progenitor cells to human diseases. Future Lipidol 1:213-225

Fargeas CA, Huttner WB, Corbeil D (2007) Nomenclature of Prominin-1 (CD133) splice variants-an update. Tiss Antig 69:602-606

Florek M, Haase M, Marzesco A-M, Freund D, Ehninger G, Huttner WB, Corbeil D (2005) Prominin-1/CD133, a neural and hematopoietic stem cell marker, is expressed in adult human differentiated cells and certain types of kidney cancer. Cell Tissue Res 319:15-26 
Florek M, Bauer N, Janich P, Wilsch-Bräuninger M, Fargeas CA, Marzesco A-M, Ehninger G, Thiele C, Huttner WB, Corbeil D (2007) Prominin-2 is a cholesterol-binding protein associated with apical and basolateral plasmalemmal protrusions in polarized epithelial cells and released into urine. Cell Tissue Res 328:31-47

Freund D, Bauer N, Boxberger S, Jørgensen B, Feldmann S, Streller U, Ehninger G, Werner C, Bornhäuser M, Oswald J, Corbeil D (2006) Polarization of human hematopoietic progenitors during contact with multipotent mesenchymal stromal cells-effects on proliferation and clonogenicity. Stem Cells Dev 15:815-829

Gashaw I, Dushaj O, Behr R, Biermann K, Brehm R, Rubben H, Grobholz R, Schmid KW, Bergmann M, Winterhager E (2007) Novel germ cell markers characterize testicular seminoma and fetal testis. Mol Hum Reprod 13:721-727

Ilio KY, Hess RA (1994) Structure and function of the ductuli efferentes: a review. Microsc Res Tech 29:432-467

Janich P, Corbeil D (2007) $\mathrm{GM}_{1}$ and $\mathrm{GM}_{3}$ gangliosides highlight distinct lipid microdomains within the apical domain of epithelial cells. FEBS Lett 581:1783-1787

Jászai J, Janich P, Farkas LM, Fargeas CA, Huttner WB, Corbeil D (2007a) Differential expression of Prominin-1 (CD133) and Prominin-2 in major cephalic exocrine glands of adult mice. Histochem Cell Biol 128:409-419

Jászai J, Fargeas CA, Florek M, Huttner WB, Corbeil D (2007b) Focus on molecules: Prominin-1 (CD133). Exp Eye Res 85:585-586

Lardon J, Corbeil D, Huttner WB, Ling Z, Bouwens L (2008) Stem cell marker prominin 1/AC133 is expressed in duct cells of the adult human pancreas. Pancreas 36:e1-e6

Lee A, Kessler JD, Read T-A, Kaiser C, Corbeil D, Huttner WB, Johnson JE, Wechsler-Reya RJ (2005) Isolation of neural stem cells from postnatal cerebellum. Nat Neurosci 8:715-719

Liu AY, Corey E, Bladou F, Lange PH, Vessella RL (1996) Prostatic cell lineage markers: emergence of BCL2 + cells of human prostate cancer xenograft LuCaP 23 following castration. Int J Cancer 65:85-89

Marzesco A-M, Janich P, Wilsch-Bräuninger M, Dubreuil V, Langenfeld K, Corbeil D, Huttner WB (2005) Release of extracellular membrane particles carrying the stem cell marker Prominin-1 (CD133) from neural progenitors and other epithelial cells. J Cell Sci 118:2849-2858

Maw MA, Corbeil D, Koch J, Hellwig A, Wilson-Wheeler JC, Bridges RJ, Kumaramanickavel G, John S, Nancarrow D, Röper K, Weigmann A, Huttner WB, Denton MJ (2000) A frameshift mutation in prominin (mouse)-like 1 causes human retinal degeneration. Hum Mol Genet 9:27-34

McDonnell TJ, Troncoso P, Brisbay SM, Logothetis C, Chung LW, Hsieh JT, Tu SM, Campbell ML (1992) Expression of the protooncogene bcl-2 in the prostate and its association with emergence of androgen-independent prostate cancer. Cancer Res 52:69406944

Miki J, Furusato B, Li H, Gu Y, Takahashi H, Egawa S, Sesterhenn IA, McLeod DG, Srivastava S, Rhim JS (2007) Identification of putative stem cell markers, CD133 and CXCR4, in hTERT-immortalized primary nonmalignant and malignant tumor-derived human prostate epithelial cell lines and in prostate cancer specimens. Cancer Res 67:3153-3161

Miraglia S, Godfrey W, Yin AH, Atkins K, Warnke R, Holden JT, Bray RA, Waller EK, Buck DW (1997) A novel five-transmembrane hematopoietic stem cell antigen: isolation, characterization, and molecular cloning. Blood 90:5013-5021

Noordzij MA, van Steenbrugge GJ, van der Kwast TH, Schröder FH (1995) Neuroendocrine cells in the normal, hyperplastic and neoplastic prostate. Urol Res 22:333-341

O'Brien CA, Pollett A, Gallinger S, Dick JE (2007) A human colon cancer cell capable of initiating tumour growth in immunodeficient mice. Nature 445:106-110
Oshima Y, Suzuki A, Kawashimo K, Ishikawa M, Ohkohchi N, Taniguchi $\mathrm{H}$ (2007) Isolation of mouse pancreatic ductal progenitor cells expressing CD133 and c-Met by flow cytometric cell sorting. Gastroenterology 132:720-732

Ricci-Vitiani L, Lombardi DG, Pilozzi E, Biffoni M, Todaro M, Peschle C, De Maria R (2007) Identification and expansion of human colon-cancer-initiating cells. Nature 445:111-115

Richardson GD, Robson CN, Lang SH, Neal DE, Maitland NJ, Collins AT (2004) CD133, a novel marker for human prostatic epithelial stem cells. J Cell Sci 117:3539-3545

Rizzo S, Attard G, Hudson DL (2005) Prostate epithelial stem cells. Cell Prolif 38:363-374

Robinson EJ, Neal DE, Collins AT (1998) Basal cells are progenitors of luminal cells in primary cultures of differentiating human prostatic epithelium. Prostate 37:149-160

Röper K, Corbeil D, Huttner WB (2000) Retention of prominin in microvilli reveals distinct cholesterol-based lipid micro-domains in the apical membrane. Nat Cell Biol 2:582-592

Schalken JA, van Leenders G (2003) Cellular and molecular biology of the prostate: stem cell biology. Urology 62:11-20

Shmelkov SV, Jun L, St Clair R, McGarrigle D, Derderian CA, Usenko JK, Costa C, Zhang F, Guo X, Rafii S (2004) Alternative promoters regulate transcription of the gene that encodes stem cell surface protein AC133. Blood 103:2055-2061

Signoretti S, Waltregny D, Dilks J, Isaac B, Lin D, Garraway L, Yang A, Montironi R, McKeon F, Loda M (2000) p63 is a prostate basal cell marker and is required for prostate development. Am J Pathol 157:1769-1775

Signoretti S, Pires MM, Lindauer M, Horner JW, Grisanzio C, Dhar S, Majumder P, McKeon F, Kantoff PW, Sellers WR, Loda M (2005) p63 regulates commitment to the prostate cell lineage. Proc Natl Acad Sci USA 102:11355-11360

Signoretti S, Loda M (2006) Defining cell lineages in the prostate epithelium. Cell Cycle 5:138-141

Singh SK, Clarke ID, Terasaki M, Bonn VE, Hawkins C, Squire J, Dirks PB (2003) Identification of a cancer stem cell in human brain tumors. Cancer Res 63:5821-5828

Singh SK, Hawkins C, Clarke ID, Squire JA, Bayani J, Hide T, Henkelman RM, Cusimano MD, Dirks PB (2004) Identification of human brain tumour initiating cells. Nature 432:396-401

Sugimura Y, Foster BA, Hom YK, Lipschutz JH, Rubin JS, Finch PW, Aaronson SA, Hayashi N, Kawamura J, Cunha GR (1996) Keratinocyte growth factor (KGF) can replace testosterone in the ductal branching morphogenesis of the rat ventral prostate. Int J Dev Biol 40:941-951

Terpe HJ, Stark H, Prehm P, Günthert U (1994) CD44 variant isoforms are preferentially expressed in basal epithelial of non-malignant human fetal and adult tissues. Histochemistry 101:79-89

Tiveron MC, Hirsch MR, Brunet JF (1996) The expression pattern of the transcription factor Phox 2 delineates synaptic pathways of the autonomic nervous system. J Neurosci 16:7649-7660

Tokar EJ, Ancrile BB, Cunha GR, Webber MM (2005) Stem/progenitor and intermediate cell types and the origin of human prostate cancer. Differentiation 73:463-473

Tran CP, Lin C, Yamashiro J, Reiter RE (2002) Prostate stem cell antigen is a marker of late intermediate prostate epithelial cells. Mol Cancer Res 1:113-121

Tsujimura A, Fujita K, Komori K, Takao T, Miyagawa Y, Takada S, Matsumiya K, Nonomur N, Okuyama A (2007) Prostatic stem cell marker identified by cDNA microarray in mouse. J Urol 178:686-691

Yamada Y, Yokoyama S, Wang XD, Fukuda N, Takakura N (2007) Cardiac stem cells in brown adipose tissue express CD133 and induce bone marrow nonhematopoietic cells to differentiate into cardiomyocytes. Stem Cells 25:1326-1333 
Yin AH, Miraglia S, Zanjani ED, Almeida-Porada G, Ogawa M, Leary AG, Olweus J, Kearney J, Buck DW (1997) AC133, a novel marker for human hematopoietic stem and progenitor cells. Blood 90:5002-5012

Yu Y, Flint A, Dvorin EL, Bischoff J (2002) AC133-2, a novel isoform of human AC133 stem cell antigen. J Biol Chem 277:2071120716

van Leenders G, Dijkman H, Hulsbergen-van de Kaa C, Ruiter D, Schalken J (2000) Demonstration of intermediate cells during human prostate epithelial differentiation in situ and in vitro using triple-staining confocal scanning microscopy. Lab Invest $80: 1251-1258$
Wang S, Garcia AJ, Wu M, Lawson DA, Witte ON, Wu H (2006) Pten deletion leads to the expansion of a prostatic stem/progenitor cell subpopulation and tumor initiation. Proc Natl Acad Sci USA 103:1480-1485

Weigmann A, Corbeil D, Hellwig A, Huttner WB (1997) Prominin, a novel microvilli-specific polytopic membrane protein of the apical surface of epithelial cells, is targeted to plasmalemmal protrusions of non-epithelial cells. Proc Natl Acad Sci USA 94:12425-12430

Zhang Q, Haleem R, Cai X, Wang Z (2002) Identification and characterization of a novel testosterone-regulated Prominin-like gene in the rat ventral prostate. Endocrinology 143:4788-4796 